\title{
COSTS OF ENERGY SHORTFALL FOR BUMBLE BEE COLONIES: PREDATION, SOCIAL PARASITISM, AND BROOD DEVELOPMENT
}

\author{
Ralph V. Cartar ${ }^{1}$ and Lawrence M. Dill \\ Behavioural Ecology Research Group, Department of Biological Sciences, Simon Fraser University, Burnaby, \\ British Columbia, Canada V5A 1S6
}

\begin{abstract}
Can. Ent. 123: 283-293 (1991)

Bumble bees rely on stored nectar to maintain high colony temperatures. This study examines some of the costs associated with exhausting stored nectar for a day in confined colonies of Bombus occidentalis Greene and B. melanopygus Nylander. Workers from energy-deprived colonies ceased incubating and allowed brood temperatures to drop to ambient levels. Workers from energy-rich colonies responded to a simulated vertebrate predator by actively moving about and buzzing loudly (apparently searching for the source of disturbance), but those from energy-depleted colonies mostly remained stationary on the comb. Workers from energy-rich colonies responded to an intruding social parasite (a Psithyrus insularis Smith queen) by chasing and attacking it, whereas those from energy-depleted colonies adopted stationary threat postures. In both cases, the more successful defensive strategy of simultaneous attack by several workers was not employed by nectar-depleted colonies. Cooling of final-instar larvae and pupae added to their development times (disproportionately so in the case of pupae), but low temperature per se did not affect their probability of survival. Hence, the costs of shortterm energy shortfall include increased susceptibility to predators and parasites and a lengthened period of development. These costs probably relate to energy stores in a nonlinear manner, providing the foundation upon which risk-sensitive foraging decisions can be based.
\end{abstract}

Cartar, R.V., et L.M. Dill. 1991. Les prix pour les colonies de Bombus d'une pénurie d'enérgie: la prédation, le parasitisme social et le développement du couvain. Can. Ent. 123: 283-293.

\section{Résumé}

Les abeilles dépendent de réserves de nectar afin de maintenir de hautes températures pour leur colonies. Cette étude examine certains prix associés à la pénurie de réserves quotidiennes de nectar encourus par des colonies confinées de Bombus occidentalis Greene et de $B$. melanopygus Nylander. Les ouvrières des colonies dont les sources d'énergie sont limitées cessent d'incuber et laissent baisser au niveau ambient la température des couvains. Les ouvrières des colonies riches en énergie répondent à une simulation d'attaque de la part d'un prédateur vertébré en se déplaçant activement et en bourdonnant fortement (cherchant apparemment la source de perturbation), tandis que celles des colonies à budget énergétique limité demeurent en majeure partie stationnaires sur les rayons. Les ouvrières des colonies à budget énergétique non limité répondent à l'intrusion d'un parasite social (une reine Psithyrus insularis Smith) en chassant ce dernier et en l'attaquant, tandis que celles des colonies à budget réduit adoptent des postures de menace stationnaires. Aux deux cas, la stratégie de défense la plus fructueuse, l'attaque en groupe, n'est pas employée par les colonies déprivées de nectar. Le refroidissement des larves en stade larvaire terminal et des pupes prolonge la durée de leur développement (d'une façon disproportionnée au cas des pupes) mais n'affecte pas la probabilité de survie. Ainsi, les prix à courte échéance du manque d'énergie incluent une plus grande susceptibilité aux prédateurs et aux parasites et une période de développement prolongée. Ces prix sont probablement reliés aux réserves énergétiques de façon non linéaire, ce qui fournit la base de toute décision alimentaire sensible à la variance.

\section{Introduction}

The goal of achieving daily energy requirements is now seen as an important factor for a forager, such that maximizing net rate of food intake must be balanced against the ${ }^{1}$ Present address: Division of Environmental Science, The Australian Museum, 6-8 College St., Sydney, NSW 2000, Australia. 
probability of death by energy shortfall (McNamara and Houston 1986). However, excepting the case of immediate death, the costs of energy shortfall (which influence the fitness expected from adopting a particular foraging strategy) are ill-defined for most animals.

Bumble bees (genus Bombus) have been favorite organisms in studies of foraging behavior (Morse 1982), in large part because their energy needs are relatively well understood and their resources easily quantified (Heinrich 1979). Bumble bees are prodigious consumers of energy. They nest predominantly in cool temperate to arctic habitats, where ambient temperatures are usually well below those optimal for brood development (Richards 1973). Despite low ambient temperatures, brood temperatures are usually maintained near $30^{\circ} \mathrm{C}$ (Hasselrot 1960 ). To do this, bees require much energy, gathered as nectar from flowers and stored in colony honey pots. Larvae grow on a mixture of honey and pollen, and workers and the queen consume nectar both for self-maintenance and for generating heat to maintain the temperature of the developing brood. Hence, stored nectar is a critical resource in allowing bumble bees to survive in cold environments.

Bumble bees forage so as to accumulate sufficient energy reserves to last them through nonforaging periods (e.g. the night; Heinrich 1979: 76). They adopt several behavioral strategies to ensure that colony energy reserves are sufficiently well stocked by the end of the foraging day. These include switching between foraging and in-colony activities (Free 1955), switching between pollen and nectar foraging (Free 1955), changing their sensitivity to predators (Cartar 1991a), adjusting their foraging rates (Cartar and Dill 1990a), and changing their sensitivity to variance risk (Cartar and Dill 1990b; Cartar 1991b).

To help understand why bumble bees employ these behavioral strategies, we examined some of the costs that bumble bees incur when their colonies run out of nectar. There is anecdotal evidence that bee colonies are capable of surviving short periods of starvation. Sladen (1912: 123) notes that bees remain in a state of suspended animation for a day or 2 during periods of inclement weather. Plowright and Pendrel (1977) found that a labreared colony which had accidentally run out of honey resumed normal development when food was re-introduced. Hence, death by starvation is an unlikely consequence of shortterm energy shortfall. To explore other costs of short-term energy shortfall, we examined how workers from well-fed and energy-depleted colonies defended their nests from a simulated mammalian predator and a social parasite (a Psithyrus queen), and examined developmental consequences of energetic shortfall, measured in terms of brood mortality and length of developmental period.

Bumble bee colonies have many predators and parasites (reviewed in Morse 1982), including mammals (especially skunks, raccoons, weasels, and foxes), usurping queens (from the same and from other bumble bee species), and obligate parasites (i.e. Psithyrus species). The effectiveness with which these threats can be met is likely to be a function of colony energy reserves; Plath (1934: 72) noted that bumble bees exhibit little or no "fighting spirit" if their colony is chilled or has run out of stored nectar. As nectar-poor colonies become torpid and cease incubating their brood (Heinrich 1979: 76), these colonies can be predicted to be relatively ineffective at repelling predators. To test this, we examined and quantified worker defense behavior in relation to colony energy status.

Bumble bees maintain their colonies at high temperatures (Seeley and Heinrich 1981). Incubation of brood is an energy-consuming activity, during which bees generate heat from their wing muscles and apply it to the brood mass (Heinrich 1974). However, when the colony exhausts its nectar supplies, brood temperatures inevitably approach ambient temperatures (e.g. Heinrich 1972). That maintenance of high brood temperatures is important to bumble bees is clear in their choice of nest site. Bumble bees reduce brood cooling by nesting in sheltered locations, by plugging the nest entrance (Wojtowski 1963), and by covering the colony with insulation. Cold-stressing laboratory colonies also causes them to build a waxen canopy over the brood (Plowright 1977). 
Temperature is known to affect brood development. Worker size is a function both of feeding rate of final-instar larvae (Plowright and Pendrel 1977) and of brood temperature; larvae that experience higher and more stable temperatures produce larger pupae (Barrow and Pickard 1985). Uninsulated laboratory colonies nesting at low ambient temperatures produce fewer workers (Vogt 1986b), because incubation of brood is more important at lower temperatures, and the growth of "cold" colonies is therefore presumably limited by the number of brood that can be successfully incubated by the workers (Vogt $1986 a$ ). In addition to retarding growth, cooling has also been suggested to stunt final size and cause developmental defects such as wrinkled wings (Heinrich 1979: 65).

To examine the developmental and mortality costs of colony cooling, we examined brood stages for which individual starvation is unimportant: final-instar larvae (which will pupate if unfed) and pupae (which require no food). This allowed us to focus on temperature-related costs of colony energy shortfall, as food was not required by brood in either treatment.

\section{Methods}

Colony Defense. Five colonies of Bombus occidentalis Greene were established in domiciles on the campus of Simon Fraser University in Burnaby, B.C. They were moved into Plexiglas-covered, uninsulated, fully enclosed observation boxes, and placed in a climatecontrolled chamber maintained at $12^{\circ} \mathrm{C}, 50 \%$ relative humidity, and a $12 \mathrm{~L}: 12 \mathrm{D}$ photoperiod. Pollen was provided in excess by adding it as a single lump to the comb. Brood temperature was monitored by resting a thermometer against a portion of the actively attended brood (see Hasselrot 1960). As brood temperatures vary across the surface of a single colony, temperature measurements are only approximate, and are most useful in contrasting a single colony across the experimental treatments. All sealed honey cells (which are often found under the current brood, and which lab-reared colonies will readily accumulate) were removed prior to the experiment, to ensure that colonies could not rely on accumulated energy stores.

The experimental procedure was as follows. Colonies spent $24 \mathrm{~h}$ in the chamber with unlimited access to $60-70 \%$ sucrose solution, provided by gravity feeder tubes. We used a "fed-starved-starved-fed" temporal design; responses to a vertebrate predator and Psithyrus intrusion were observed first at the 24-h point (when the colony was well-provisioned with honey, =F1), next $12 \mathrm{~h}$ after the feeder tubes and all colony nectar stores were removed $(=\mathrm{S} 1)$, again $12 \mathrm{~h}$ after trial $\mathrm{S} 1(=\mathrm{S} 2)$, and finally $3 \mathrm{~h}$ after unlimited access to sucrose solution was restored $(=\mathrm{F} 2)$. This design allowed us to test the reversibility of any effects of energetic shortfall. Water was provided in the feeder tubes during the S1 and $\mathrm{S} 2$ treatments. Colony nectar reserves were removed with a $1-\mathrm{mL}$ disposable plastic pipette and cotton-tipped swabs, but some nectar residues were always present afterward.

Bumble bees are very sensitive to any physical disturbance of their colony, and are quick to attack any vertebrate causing such disturbance (Plath 1934: 74). To simulate a vertebrate predator, we agitated colonies using a cylindrical vibrator. The vibrator was strapped to the colony nest box with a thick rubber band, and activated for $20 \mathrm{~s}$, during which worker responses were videotaped. We used a single vibration frequency, to which bees typically responded with great agitation.

Five behavioral responses to vibration were classified on a scale of increasing intensity. These are, from lowest to highest intensity: (1) stand-remaining motionless; (2) stand and jerk-remaining in one location, but moving from side to side; (3) walk-moving slowly around the colony; (4) run-moving rapidly around the colony, without assistance of the wings; and (5) fly-flying around the nest. A further category (out of sight) applied to bees who were lost from sight beneath the colony surface or at its margins. Bees also buzzed their wings when agitated, and we recognized two qualitative intensities of wing 
buzzing: low and high frequency. To compare worker responses to vibration of their colonies across the four treatment groups, we recorded the number of seconds during colony agitation that each bee spent in states 1 through 5 and out of sight, summing to $20 \mathrm{~s}$. In addition, the times spent in low- or high-intensity wing buzzing were recorded.

To test for colony effectiveness at repelling usurpation, we placed a Psithyrus insularis Smith queen on the colony comb, and videotaped subsequent worker responses. Psithyrus insularis is a common parasite of $B$. occidentalis in the wild (unpublished data). The Psithyrus was introduced between 20 and $40 \mathrm{~s}$ after the vibration trial had ended, and was left in the colony until at least four different workers had been physically contacted (total time between 20 and 70 s). The same Psithyrus individual was used in all trials for all colonies.

Behavioral responses were recorded for each worker contacted by the Psithyrus intruder on a scale of increasing intensity, as follows: (1) no response-no apparent reaction to the intruder; (2) leg up - one leg (on the side closest to the intruder) raised over the back; (3) twist —one or two legs up, and body axis rotated up to $90^{\circ}$ so as to present ventral surface and sting to the intruder; (4) on back-lying on back with legs spread widely and back against the ground, sting raised in the air, and jaws open; (5) chaseintruder actively pursued by worker, but not contacted (often because the intruder fled); and (6) fight-intruder physically attacked. Behaviors 2-4 are previously described threat displays of increasing intensity (Plath 1934: 73; Heinrich 1979: 17), and behavior 4 is considered to be less agressive than pursuit (Alford 1975: 64). The average number of bees per colony per trial was $10.6(\mathrm{SD}=3.8$, range $=4-17)$.

Brood Development. To examine the developmental costs of cooling, we compared the emergence pattern of brood that had cooled for a short period with that of brood that had remained warm, but in neither case attended by workers, so as to separate effects of being attended by workers from effects of temperature per se. We used domicile-established colonies of two bumble bee species: $B$. melanopygus Nylander $(n=5)$ and $B$. occidentalis ( $n=6$, including four used in the colony defense experiment). Pupae were removed from each colony, and final-instar larvae from some of these, and divided into two treatment groups; one was placed in a climate chamber maintained at $10-12^{\circ} \mathrm{C}$, and the other was placed under an infrared heat lamp and maintained at $28-33^{\circ} \mathrm{C}$ (the temperature of a thermometer placed directly under the light and adjacent to the brood). To maintain humidity, brood in the warm treatment were placed in a glass terrarium covered with Plexiglas and containing dampened paper. Both groups were removed after $20 \mathrm{~h}$ and placed in separate observation boxes provided with at least four (and at most six) attendant workers, who had unlimited access to nectar and pollen (in the case of larvae). Whenever possible, we split clumps containing brood at the same stage of development (and from the same location on the colony) into both treatments. When brood clumps were too small to be split, a coin toss assigned brood to treatment group. Colonies were kept in a room at $22-27^{\circ} \mathrm{C}$, and newly emerged adults were removed daily.

\section{Results}

Colony Defense. To summarize behavioral responses to simulated vertebrate predation across different levels of colony energy condition, we performed a principal components analysis (PCA) on the time spent by each bee in each activity during a trial, pooling data from all colonies and treatments $(n=375)$. The first principal component (PC1) explained $28.6 \%$ of the variance in the original data, and contrasted "stand" and "buzz wings (low)" with all other behaviors (Table 1). Hence, the greatest proportion of the variance among behaviors adopted by bees in the face of a simulated vertebrate predator was accounted for by two general syndromes: immobility (low PC1) and movement (high PC1). The 
Table 1. Correlations between behavioral variables and the first principal component (PC1) for predation and social parasitism experiments

\begin{tabular}{lrllr}
\hline & & & & Social parasitism \\
\cline { 1 - 1 } Behavior & PC1 & & Behavior & PCl \\
\hline Stand & -0.96 & & No response & 0.07 \\
Stand and jerk & 0.24 & & Leg up & -0.84 \\
Walk & 0.90 & & Twist & -0.36 \\
Run & 0.08 & & On back & -0.61 \\
Fly & 0.19 & & Chase & 0.59 \\
Out of sight & 0.21 & & Fight & 0.65 \\
Buzz wings (high) & 0.60 & & & $33.3 \%$ \\
Buzz wings (low) & -0.23 & & & 3 \\
Variance explained & $28.6 \%$ & & &
\end{tabular}

second principal component explained $15.1 \%$ of the variance in the original data, and did not vary with treatment in a consistent manner among colonies.

Worker responses to vibration of their colony (PC1) were strongly affected by the condition of colony energy reserves [one-way ANOVAs $(P=0.0001$ in all cases): colony $1-F=21.80, n=106$; colony $2-F=74.73, n=67$; colony $3-F=10.40, n=89$; colony $4-F=23.52, n=65$; colony $5-F=40.32, n=48]$. There was a significant decrease in PC1 (i.e. an increase in immobility) when colony reserves were depleted, but this trend was significantly reversed when colony reserves were restored (Fig. 1A).

Colony energy shortfall was accompanied by a drop in brood temperature, and there was a significant positive relationship between brood temperature and PC1 (i.e. mobility; Fig. 1B). In Figure 1B, data are pooled across five colonies and four treatments, but the positive correlation between $\mathrm{PCl}$ and brood temperature also held within each colony ( $P=0.031$, one-tailed sign test).

To compare worker responses to social parasitism (i.e. Psithyrus intrusion) across different levels of colony energy condition, we performed a PCA on the behavioral data set, using all treatments for all colonies. The data consisted of the proportional use of each behavior type for each colony and treatment $(n=20)$. PC1, summarizing $33.3 \%$ of the variance in the data, contrasted "passive" responses to the Psithyrus (i.e. leg up, twist, and on back) with "active" responses (i.e. chase and fight; Table 1), but nonresponses were not important. The second principal component, which explained $28.1 \%$ of the variance in the original data, was unrelated to treatment.

As was the case for responses to a simulated predator, worker responses to social parasitism (PC1) were affected by colony energy condition (one-way ANOVA, $F=7.45$, $n=20, P=0.002$ ). Workers from fed treatments tended to confront the Psithyrus actively (high PC1), but those from starved treatments favored passive confrontation (low PC1). This difference was significant, and reversible according to treatment (Fig. 2A). Again, colony treatment affected brood temperature, and $\mathrm{PCl}$ and brood temperature were significantly correlated (Fig. 2B). The data in Figure 2B were pooled across five colonies and four treatments, but the positive relationship between $\mathrm{PCl}$ and brood temperature also held within each colony ( $P=0.031$, one-tailed sign test).

There was a clear contextual difference in occurrence of the two types of wing buzzing. The high-frequency buzzing was very audible. Actively moving workers signal their aggressiveness by buzzing loudly (e.g. Plath 1934: 66); note the positive correlation between buzz wings (high) and PC1 (Table 1). In contrast, the low-frequency wing buzzing was quiet, and was associated with workers who had entered torpor and were shivering to warm up (Heinrich 1979), hence the negative correlation of this variable with PC1 

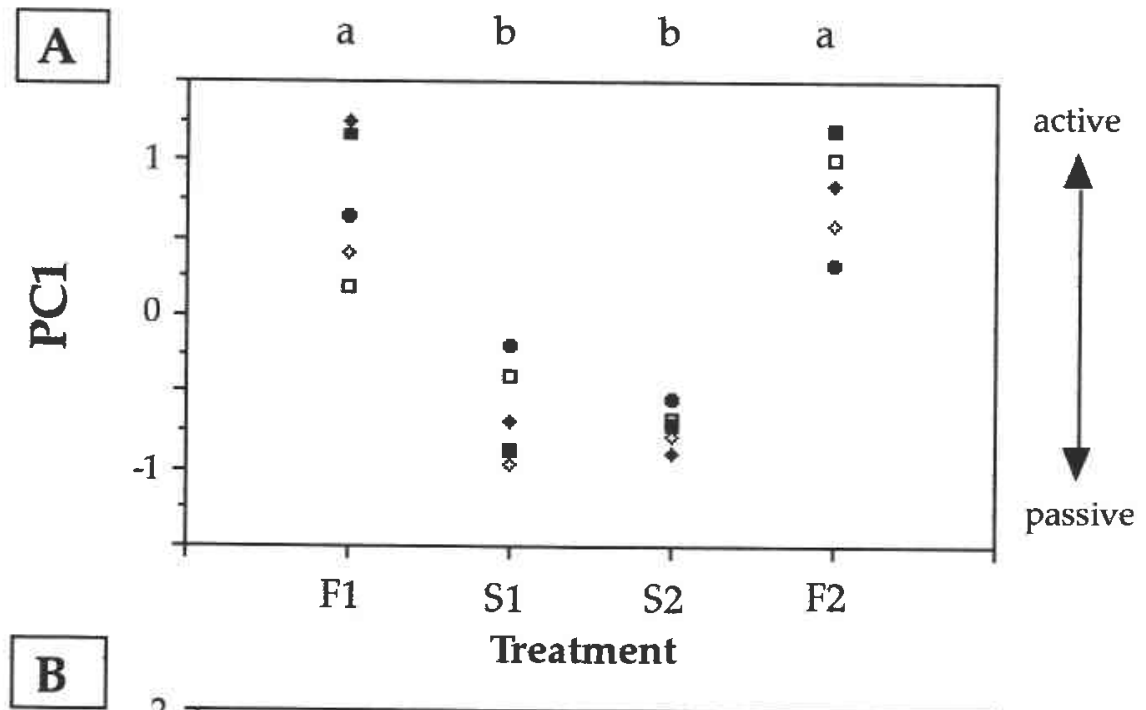

Treatment

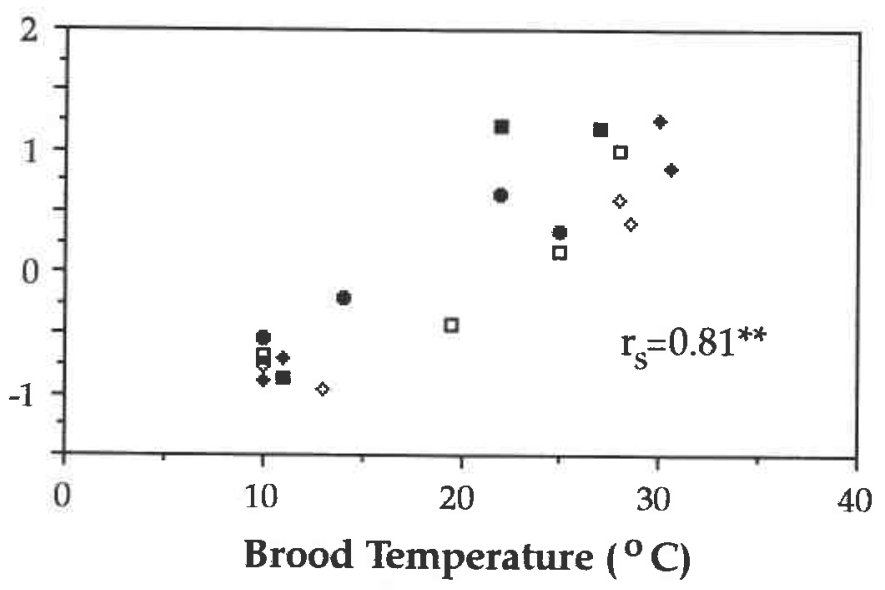

active

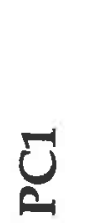

FlG. 1. (A) Mean response of workers to colony vibration (PC1) changes with condition of colony energy reserves. Treatments labelled with the same letter are not significantly different (Tukey's HSD, $P<0.05$ ). Colony symbols are as follows: 1 , open square; 2 , solid diamond; 3 , solid circle; 4 , open diamond; 5 , solid square. (B) Relationship between mean response of workers to colony vibration $(\mathrm{PCl})$ and colony temperature. Workers from warm colonies were more likely to move around the colony (high $\mathrm{PC} 1$ ), whereas those from cool (= depleted) colonies tended to remain stationary (low PC1). Colony symbols as in (A).

(Table 1). High buzzing can be viewed as a threat display, and low buzzing as thermoregulatory behavior.

Brood Development. Heated pupae emerged earlier than cooled pupae in eight of the 11 colonies (Table 2). Relative to warming, cooling pupae for $20 \mathrm{~h}$ added an average of $52.8 \mathrm{~h}$ to their development time. This difference is significant (Wilcoxon matched-pairs test, $T=11$, one-tailed $P=0.027$ ). In three colonies, the cooled brood emerged (on average) before the warmed brood (Table 2). This is not unexpected, as pupae were not all of equal age when assigned to treatments, and were assigned in clumps of same-aged individuals. Thus, by chance alone, more older pupae could have been assigned to the cold treatment. However, such developmental differences due to age cannot explain the significant overall depression in development time for cooled pupae, as the net expectation 


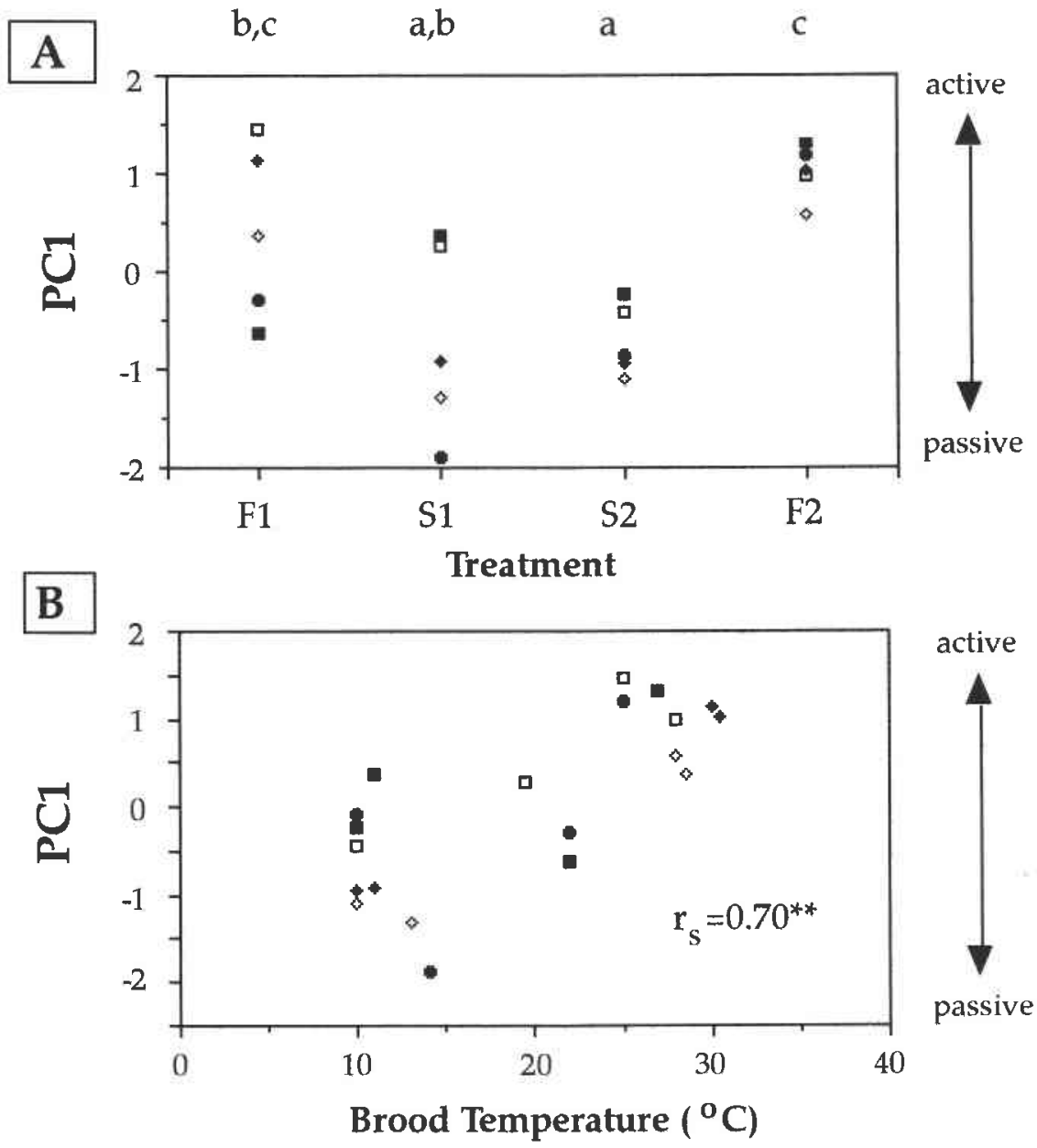

FIG. 2. (A) Mean response of workers to a Psithyrus intruder (PC1) changes with condition of colony energy reserves. Treatments labelled with the same letter are not significantly different (Tukey's HSD, $P<0.05$ ). Colony symbols are as follows: 1 , open square; 2 , solid diamond; 3 , solid circle; 4 , open diamond; 5 , solid square. (B) Relationship between mean response of workers to a Psithyrus intruder (PC1) and colony temperature. Workers from warm colonies tended to chase and directly attack the intruder (high PC1), whereas those from $\operatorname{cool}(=$ depleted) colonies tended to adopt a stationary threat position upon contact with the intruder (low PC1). Colony symbols as in (A).

from this factor alone is for no developmental difference (given random assignment of brood to treatments). Because a 20 -h cooling resulted in a 52.8-h delay in growth, the cost of cooling in pupae is a disproportionately lengthened period of development (increased by $164 \%$ from $20 \mathrm{~h}$ ). The variation in emergence date (measured as SD, Table 2) was not different between the treatments (Wilcoxon matched-pairs test, $T=29, P>0.1$ ), suggesting that temperature did not exert different effects on the different ages of brood contained within each sample.

Heated final-instar larvae emerged significantly earlier than cooled larvae in two of the five colonies (Table 3), the average difference in median emergence date being 1.2 days. The expectation based on no development during cooling and normal development during warming is for a 20 -h difference in emergence times between the groups. 
Table 2. Differences in median date of emergence for pupae that were heated $(\mathrm{H})$ or cooled $(\mathrm{C})$ for $20 \mathrm{~h}$. Species codes: $\mathrm{O}=$ Bombus occidentalis and $\mathrm{M}=$ B. melanopygus

\begin{tabular}{|c|c|c|c|c|c|c|}
\hline \multirow[b]{2}{*}{ Species } & \multirow[b]{2}{*}{ Colony } & \multirow{2}{*}{$\begin{array}{l}\text { Difference }(\mathrm{C}-\mathrm{H}) \text { in } \\
\text { median emergence } \\
\text { date (days) }\end{array}$} & \multicolumn{2}{|c|}{$\begin{array}{c}\text { Number of bees } \\
\text { emerged }\end{array}$} & \multicolumn{2}{|c|}{$\begin{array}{c}\text { Standard deviation } \\
\text { of emergence date } \\
\text { (days) }\end{array}$} \\
\hline & & & $\mathrm{H}$ & C & $\mathrm{H}$ & C \\
\hline $\mathrm{O}$ & 1 & 4 & 24 & 26 & 5.5 & 5.2 \\
\hline $\mathrm{O}$ & 2 & 3 & 47 & 42 & 5.4 & 5.4 \\
\hline $\mathrm{O}$ & 3 & -1 & 10 & 3 & 3.0 & 0.6 \\
\hline $\mathrm{O}$ & 5 & 2 & 26 & 31 & 4.1 & 3.5 \\
\hline O & 6 & 6 & 11 & 9 & 3.2 & 2.5 \\
\hline $\mathrm{O}$ & 7 & 5.5 & 10 & 7 & 1.6 & 2.7 \\
\hline M & 8 & -1 & 22 & 11 & 1.2 & 0.9 \\
\hline M & 9 & 2.5 & 3 & 2 & 0.6 & 2.1 \\
\hline M & 10 & 5 & 23 & 11 & 1.4 & 1.3 \\
\hline $\mathbf{M}$ & 11 & -4.5 & 4 & 8 & 2.1 & 0.6 \\
\hline $\mathbf{M}$ & 12 & 3 & 5 & 7 & 0.9 & 1.7 \\
\hline \multicolumn{2}{|c|}{ Unweighted means } & 2.2 & & & 2.6 & 2.4 \\
\hline
\end{tabular}

Although this sample is too small to establish the effect, it seems that larval cooling does not increase development time beyond the $20 \mathrm{~h}$ of "shutdown".

Brood mortality did not differ between experimental treatments (Table 4; Wilcoxon matched-pairs test, $T=24.5, n=11, P>0.1$ ), suggesting that there was no consistent mortality cost directly due to short-term cooling. We pooled pupal and larval mortality estimates, as we could not tell whether dead pupae were pupae or larvae at the time of cooling/heating. Incidences of abnormality (i.e. curly wings, no pile) were virtually nonexistent, and were only slightly more common in the cooled (two cases from one colony) than in the heated brood (zero cases). The brood-cooling experiment used both growing colonies (producing workers) and reproductive colonies (producing queens and males; Table 4). There were no obvious differences among brood from growing and reproductive colonies in the effects of the experimental treatments.

\section{Discussion}

Based on these findings, we conclude that colonies that have exhausted their supply of stored nectar will be less able to defend themselves effectively against a vertebrate predator. Such a predator is more likely to be deterred by workers who are actively moving around searching for the source of disturbance-and therefore more likely to intercept the predator before it damages the colony, and to involve more than one worker in the attack-

Table 3. Differences in median date of emergence for final-instar larvae that were heated $(\mathrm{H})$ or cooled $(\mathrm{C})$ for $20 \mathrm{~h}$. Species codes: $\mathrm{O}=$ Bombus occidentalis and $\mathrm{M}=\boldsymbol{B}$. melanopygus. Chi-square represents a KolmogorovSmirnov two-sample one-tailed test for large samples, which is conservative when applied to small samples (Siegel 1956). The average median difference between treatments was 1.2 days

\begin{tabular}{|c|c|c|c|c|c|c|}
\hline \multirow[b]{2}{*}{ Species } & \multirow[b]{2}{*}{ Colony } & \multirow{2}{*}{$\begin{array}{l}\text { Difference }(\mathrm{C}-\mathrm{H}) \text { in } \\
\text { median emergence } \\
\text { date (days) }\end{array}$} & \multirow[b]{2}{*}{ Chi-square } & \multirow[b]{2}{*}{$P$} & \multicolumn{2}{|c|}{$\begin{array}{c}\text { Number of bees } \\
\text { emerged }\end{array}$} \\
\hline & & & & & $\mathrm{H}$ & $\mathrm{C}$ \\
\hline $\mathrm{O}$ & 1 & 5 & 9.46 & 0.01 & 9 & 13 \\
\hline $\mathrm{O}$ & 3 & -3 & 2.84 & 0.2 & 10 & 8 \\
\hline M & 9 & -1 & 1.49 & 0.3 & 7 & 16 \\
\hline $\mathbf{M}$ & 10 & 3 & 6.00 & 0.05 & 3 & 3 \\
\hline M & 11 & 1 & 3.47 & 0.1 & 6 & 11 \\
\hline
\end{tabular}


Table 4. Mortality of pupae and final-instar larvae that were experimentally cooled (C) or heated (H). Species codes: $\mathrm{O}=$ Bombus occidentalis and $\mathrm{M}=B$. melanopygus. There is no mortality difference between the treatments

\begin{tabular}{ccccl}
\hline & & \multicolumn{2}{c}{$\%$ mortality } & \\
\cline { 2 - 3 } Species & Colony & $\mathrm{H}$ & $\mathrm{C}$ & Brood produced \\
\hline $\mathrm{O}$ & 1 & 7.7 & 0 & Males, queens \\
$\mathrm{O}$ & 2 & 0 & 4.5 & Males, queens \\
$\mathrm{O}$ & 3 & 9.1 & 8.3 & Workers, queens \\
$\mathrm{O}$ & 5 & 7.1 & 3.1 & Males \\
$\mathrm{O}$ & 6 & 0 & 7.7 & Males \\
$\mathrm{O}$ & 7 & 9.1 & 0 & Workers \\
M & 8 & 0 & 3.7 & Workers \\
M & 9 & 33.3 & 37.5 & Workers \\
M & 10 & 9.4 & 21.4 & Males \\
M & 11 & 70.6 & 55.6 & Workers, males \\
M & 12 & 16.7 & 12.5 & Males \\
Unweighted means & & 14.8 & 14.0 & \\
\hline
\end{tabular}

than by workers standing motionless on the comb. Most of the workers who stood motionless or buzzed their wings at low frequency when their colony was vibrated in treatments S1 and S2 had ceased incubating brood and appeared torpid, allowing their thoracic temperatures to fall to ambient levels. They were therefore incapable of much movement. Because bumble bees rely upon group attack to deter vertebrate predators, a nectar-poor colony is likely to be less successful in defense.

The among-treatment differences in responses to parasitism were also dramatic. When a colony was energy-rich, its workers usually chased and attacked the Psithyrus queen, often causing her to flee for safety under the colony or hide at the side of the colony. The intruder was often ' balled' by several workers simultaneously (described by Plath 1934: 49; Free and Butler 1959: 73), a tactic that effectively immobilized her, but at some cost in worker mortality (of up to four workers per trial). In contrast, when a colony was energypoor, there was no effective concerted attack on the intruder. Workers who encountered the $P$ sithyrus usually adopted an aggressive (but immobile) stance, and did not pursue her. The intruder was therefore never overwhelmed by a mob of workers. Indeed, she often directly attacked workers one-by-one. Odor is an important means by which colonies recognize foreign bees (Plowright and Fuller 1988), but an intruder begins to absorb colony odor within an hour or 2 of its intrusion (Free and Butler 1959: 67). A foreign bee consequently will often be "accepted" in a colony (i.e. not attacked) after having successfully spent some time in it. Hence, a Psithyrus can successfully invade an energy-poor colony either by physically dominating its workers, or by gaining time to absorb enough colonyspecific odor to ensure acceptance even after colony energy stores later have been replenished.

The finding of risk-sensitive foraging based on colony energetic requirements (Cartar and Dill 1990a; Cartar 1991 b) implies that the relationship between stored energy and the costs of energetic shortfall are nonlinear (Real and Caraco 1986). Based on the findings of the colony defense study, two nonlinear scenarios relating colony energy stores to costs are conceivable. First, a step function is expected if bees maintain constant high temperatures (and therefore readiness to repel intruders) until all colony nectar is exhausted, after which all bees become torpid (and therefore ineffective at repelling intruders). This generates a rapid, step-like increase in susceptibility to predation or parasitism. Second, a sigmoid function relating colony energy stores to costs is expected if colonies conserve nectar by having workers "shut down" sequentially, so that the number of active individuals directly reflects colony energy supplies. If predators or parasites are more effectively repulsed by a group of bees than by a single bee, then accelerating returns from increases 
in the number of active, defending bees are expected. This effect must eventually reach some asymptote after which additional attacking bees do not improve the likelihood of enemy repulsion, producing decelerating returns (e.g. Oster and Wilson 1978). Overall, then, a sigmoid cost function is produced. Which of the two cost functions holds probably depends on the range over which, and the rapidity with which, the shortfall is experienced; colonies who have just exhausted their energy stores contain both torpid and nontorpid bees (unpublished data), suggesting some period of gradual "shutdown".

Because mortality differences between heated and cooled brood were negligible, the primary cost to cooling of the brood is a time, or "opportunity" cost. Moderate cooling of brood for a given period adds to their development time; the time added varied between the length of the period of cooling (for final-instar larvae) and $164 \%$ above the length of the period of cooling (for pupae). Bumble bee colonies optimize reproductive effort with a "bang-bang" reproductive strategy, whereby all resources are used for colony growth (i.e. production of workers) until some switch point near the end of the season, when resources are diverted entirely to production of reproductives (Oster and Wilson 1978). The larger the colony at this switch point, the greater is its capacity for production of reproductives. Because bumble bees face a limited growing season, any developmental delays (caused by brood cooling) will result in a smaller final colony size, and therefore lower colony fitness through decreased production of reproductive individuals.

It is possible that workers are sensitive to the differing thermal susceptibilities of larvae and pupae. In the colony defense studies, bees from energy-deprived colonies preferentially brooded pupae. Alford (1975: 64) also noted that pupal cocoons are especially "attractive" to incubating bees. However, pupae also represent greater reproductive value to the colony (they are closer to emergence, at which time fitness benefits can be realized), and their preferential brooding would be expected for this reason alone. Another possible cost of cooling, not measured in this study, is increased susceptibility to disease. Honey bee larvae are more likely to succumb to disease when brood temperatures are low (reviewed in Seeley 1985: 111), and the same may be true for bumble bee larvae.

Because third-instar larvae increase their development period no longer than their period of cooling, there seems to be a linear relationship between development rate and temperature for temperatures exceeding some threshold value. However, because the increase in pupal developmental period exceeded the period of cooling, the possibility exists that costs of cooling might increase disproportionately with length of cooling period in this case. In addition, the typical logistic growth of social insect colonies (Oster and Wilson 1978) means that the consequences of a given period of developmental shutdown will vary according to colony size. In both cases, such nonlinearity could provide a basis for risk-sensitive diet choice by foragers.

In conclusion, as has been previously reported by many authors, bumble bee colonies are capable of surviving periods of short-term energy deficit. Colony survival is achieved by "shutting down" metabolically (i.e. entering torpor), and allowing normally high colony temperatures to fall to ambient levels. If the energy-poor condition does not last beyond a day or 2, colonies can resume normal functioning when conditions improve. However, there are several costs to such energetic shortfall. As detailed in this study, these include less concerted defense against attacks by vertebrate predators and attempts at reproductive usurpation by social parasites. Developmental period is also lengthened (disproportionately so in the case of pupae), resulting in slower colony growth. Slower colony growth should result in smaller colony size at the time of reproduction, and therefore reduced reproductive success. The predation, social parasitism, and brood-cooling costs all appear to relate to energy stores in a nonlinear manner, thereby forming the foundation upon which risksensitive foraging decisions (Cartar and Dill 1990a; Cartar 1991b) can be based. 


\section{Acknowledgments}

We thank Ian Parnell for his help with the video analysis, Guy Martel and Yves Carrière for the French translations, and Lee Gass, Mary Reid, Dave Stephens, Nico Verbeek, Mark Winston, and Ron Ydenberg for comments on the manuscript. This work was supported by NSERC grant A6869 to LMD, and by NSERC and SFU scholarships to RVC.

\section{References}

Alford, D.V. 1975. Bumblebees. Davis-Poynter, London. 352 pp.

Barrow, D.A., and R.S. Pickard. 1985. Larval temperature in brood clumps of Bombus pascuorum (Scop.). $J$. Apicul. Res. 24: 69-75.

Cartar, R.V. 1991a. Colony energy requirements affect response to predation risk in foraging bumble bees. Ethology. In press.

1991b. A test of risk-sensitive foraging in wild bumble bees. Ecology. In press.

Cartar, R.V., and L.M. Dill. 1990 a. Why are bumble bees risk-sensitive foragers? Behav. Ecol. Sociobiol. 26: 121-127.

$1990 \mathrm{~b}$. Colony energy requirements affect the foraging currency of bumble bees. Behav. Ecol. Sociobiol. In press.

Free, J.B. 1955. The division of labour within bumblebee colonies. Insectes Soc. 2: 195-212.

Free, J.B., and C.G. Butler. 1959. Bumblebees. Collins, London. 208 pp.

Hasselrot, T.B. 1960. Studies on Swedish bumblebees. Opusc. Ent., Suppl. 17. Lund.

Heinrich, B. 1972. Patterns of endothermy in bumblebee queens, drones and workers. J. comp. Physiol. 77 : 65-79.

1974. Thermoregulation in bumblebees. I. Brood incubation by Bombus vosnesenkii queens. J. comp. Physiol. 88: 129-140.

1979. Bumblebee Economics. Harvard Univ. Press, Cambridge, MA. 245 pp.

McNamara, J.M., and A.I. Houston. 1986. The common currency for behavioral decisions. Am. Nat. 127: 358378.

Morse, D.H. 1982. Behavior and ecology of bumble bees. pp. 245-322 in Hermann, H.R. (Ed.), Social Insects, Vol. 3. Academic Press, New York, NY. 459 pp.

Oster, G.F., and E.O. Wilson. 1978. Caste and Ecology in the Social Insects. Princeton Univ. Press, Princeton, NJ. 352 pp.

Plath, O.E. 1934. Bumblebees and Their Ways. MacMillan, New York, NY. 201 pp.

Plowright, R.C. 1977. Nest architecture and the biosystematics of bumble bees. Proc. Eighth Int. Cong. Int. Union Stud. Soc. Insects (Wageningen): 183-185.

Plowright, R.C., and G.A. Fuller. 1988. The role of intruder behavior in nestmate recognition by bumble bees (Hymenoptera: Apidae). Can. J. Zool. 66: 2847-2851.

Plowright, R.C., and B.A. Pendre]. 1977. Larval growth in bumble bees (Hymenoptera: Apidae). Can. Ent. 109: 967-973.

Real, L.A., and T. Caraco. 1986. Risk and foraging in stochastic environments: Theory and evidence. A. Rev. Ecol. Syst. 17: 371-390.

Richards, K.W. 1973. Biology of Bombus polaris Curtis and B. hyperboreus Schonherr at Lake Hazen, Northwest Territories (Hymenoptera: Bombini). Quaest. ent. 9: 115-157.

Seeley, T. 1985. Honeybee Ecology. Princeton Univ. Press, Princeton, NJ. 201 pp.

Seeley, T., and B. Heinrich. 1981. Regulation of temperature in the nests of social insects. pp. 159-234 in Heinrich, B. (Ed.), Insect Thermoregulation. Wiley, New York, NY. 328 pp.

Siegel, S. 1956. Nonparametric Statistics for the Behavioral Sciences. McGraw-Hill, New York, NY. 312 pp.

Sladen, F.W.L. 1912. The Humble Bee. MacMillan, London. 283 pp.

Vogt, F.D. 1986a. Thermoregulation in bumblebee colonies. I. Thermoregulatory versus brood-maintenance behaviors during acute changes in ambient temperature. Physiol. Zool. 59: 55-59.

1986b. Thermoregulation in bumblebee colonies. II. Behavioral and demographic variation throughout the colony cycle. Physiol. Zool. 59: 60-68.

Wojtowski, F. 1963. Studies on heat and water economy in bumble-bee nests (Bombinae). Zool. Pol. 13: 1936.

(Date received: 31 July 1990; date accepted: 18 October 1990) 